\title{
GCU
}

Glasgow Caledonian

University

University for the Common Good

\section{Broadcasting personalities: the relationship between occupation and music preferences in the BBC Radio programme Desert Island Discs}

Knox, Don; MacDonald, Raymond

Published in:

Psychology of Music

DOI:

$10.1177 / 0305735616670497$

Publication date:

2017

Document Version

Author accepted manuscript

Link to publication in ResearchOnline

Citation for published version (Harvard):

Knox, D \& MacDonald, R 2017, 'Broadcasting personalities: the relationship between occupation and music preferences in the BBC Radio programme Desert Island Discs', Psychology of Music, vol. 45, no. 5, pp. 645664. https://doi.org/10.1177/0305735616670497

\section{General rights}

Copyright and moral rights for the publications made accessible in the public portal are retained by the authors and/or other copyright owners and it is a condition of accessing publications that users recognise and abide by the legal requirements associated with these rights.

Take down policy

If you believe that this document breaches copyright please view our takedown policy at https://edshare.gcu.ac.uk/id/eprint/5179 for details of how to contact us. 


\title{
Broadcasting personalities: The relationship between occupation and music preferences in the BBC Radio programme Desert Island Discs
}

\begin{abstract}
This research examines the music choices of interviewees on the BBC Radio programme Desert Island Discs over a 72 year period. In the programme, individuals with a public profile related to high achievement in their chosen occupation identify several pieces of their favourite music. Publicly stated music preferences offer insights on how individuals construct and wish to communicate crucial aspects their identities. We propose that, in this context, occupation is related to music preferences. We investigate this relationship within the framework of Holland's RIASEC model of vocational personality types, previously ignored by research into music preferences. We consider music preferences in terms of the five-dimension MUSIC model of music preferences, and preference for acoustical attributes of chosen music. Results demonstrate several significant associations between RIASEC occupation types and MUSIC preference dimensions, and also a main effect for RIASEC type on acoustical music attributes such as tempo, energy and loudness.
\end{abstract}

\section{Keywords}

Music preferences, music attributes, personality, Desert Island Discs, RIASEC 
This research explores the relationship between occupation and music preferences. We investigate this relationship in the context of publicly expressed music preferences of individuals who have a public profile related to their occupation. Public expression of music preferences can be used as a representation of one's identity (Hargreaves, Miell \& MacDonald, 2002; Warlick, 2006), and there is evidence that sharing music libraries is related to management of identity (Voida, Grinter \& Ducheneaut, 2006). Musical tastes can reinforce self-view, and communicate that information to others (Rentfrow \& Gosling, 2003; Tarrant, North \& Hargreaves, 2002). In the current research we consider music preference in two ways, each of which has been the focus for previous research on music preferences and individual differences: 1. genre-based dimensions of preference as defined by the MUSIC model of music preference (Rentfrow, Goldberg \& Levitin, 2011; Rentfrow et al., 2012) and 2. acoustical attributes of the music. Chosen occupation is itself an expression of personality (Holland, 1997), and there is a significant body of research concerned with the exploration of key factors surrounding an individual's career choices. In the current research, occupation is considered within the framework of the RIASEC model of vocational personality (Holland, 1994, 1997; Holland, Powell \& Fritzsche, 1994).

The context for the current research is the BBC Radio programme Desert Island Discs (British Broadcasting Corporation, 2015). People who are interviewed on the programme have a public profile based on high achievement in their chosen occupation, and during the programme they identify several pieces of their favourite music. Given the Desert Island Discs programme is broadcast to the general public, interviewees may be especially aware of how their music choices are viewed, and how consistent these are with their public profile/identity as an actor, writer, politician and so-forth. This is therefore a unique context where the interviewee may be concerned with management of the impression they convey, and this impression is related to both their occupation and music choices. In this research, we examine the music choices of interviewees on the Desert Island Discs programme over a period of 72 years. 


\section{Desert Island Discs}

Desert Island Discs has been broadcast since 1942 (BBC, 2015). Interviewees are asked to imagine they have been marooned on a desert island, and must consider eight pieces of music they might take with them. The programme is essentially an autobiographical account of the interviewee's life experiences, using their music choices as the context for discussion. The BBC recently made the Desert Island Discs archive available online, comprising recordings of episodes broadcast since 1942, a database of participants, their music choices, occupation and date of broadcast. The archive is an important cultural record, representing an exploration of life experiences and music spanning a period of over 70 years. The programme has been the subject of research examining responses to interview questions (Heritage, 1998); fundamental pitch of the speech of interviewees (Harrington, Palethorpe \& Watson, 2007; Reubold, Harrington \& Kleber, 2010); gender and 'politeness' (Mullany, 1999); the role of work in people's lives (Orbach, 2008); and career and life experience (Cohen \& Duberley, 2013). Surprisingly, to date the archive has not been utilised by music researchers to any great extent.

\section{Music preferences and personality}

There is growing research which underlines links between personal music preferences, social identity and behaviour (North \& Hargreaves, 2007; North, Hargreaves \& O'Neill, 2000; Tekman \& Hortacsu, 2002) including social group dynamics (Tarrant et al., 2002). Developing an insight into individuals' music preference can reveal important aspects of personality because music is crucially involved how we construct, maintain and negotiate our identities (MacDonald, Hargreaves \& Miell, 2002; MacDonald, Hargreaves \& Miell, in press).

Music genre has been the focus of much research seeking to align personality facets with music

preferences. Earlier research examined links between personality facets and preference for individual 
music genres (Daoussis \& McKelvie, 1986; Litle \& Zuckerman, 1986; Rawlings \& Ciancarelli, 1997; Wheeler, 1985), whereas subsequent research has focused more upon relationships between personality and preference for music 'dimensions' which may encompass multiple genres. The popular four dimension model of Rentfrow and Gosling (2003, 2006, 2007) comprises the music dimensions Reflective and Complex (incorporating genres such as classical, blues, jazz folk, and international), Intense and Rebellious (inc. rock, alternative, metal and punk), Upbeat and Conventional (inc. pop, country, oldies, soundtracks) and Energetic and Rhythmic (inc. dance, funk, rap/hip-hop and soul/R\&B). The model is the basis for the Short Test on Music Preference (STOMP), later extended to incorporate more genres into the four dimensions, resulting in the STOMPR scale (STOMPR 2015). This work has subsequently been extended in research that has sought to examine music preferences from the perspective of affective response of the listener to music excerpts (Rentfrow et al., 2011). The result is a five-dimension model of underlying music preferences, where each dimension encompasses genres which have shared auditory features and psychological attributes associated with the music (for example aggressive, intelligent). The model has been found to be robust, resembling and converging with previous research on preference dimensions (Rentfrow et al., 2011). Subsequent research supports the model, whilst suggesting individual auditory and psychological attributes of music account for greater variance in music preferences than genre category (Rentfrow et al., 2012). The dimensions combine to form the MUSIC model: Mellow (quiet, relaxing, slow, thoughtful, including genres such as international, electronica); Unpretentious (unaggressive, uncomplicated, soft, acoustic, including genres such as country); Sophisticated (intelligent, complex, dynamic, including genres such as classical, jazz); Intense (loud, aggressive, e.g. rock and punk); Contemporary (rhythmic, danceable, percussive, e.g. rap, funk, soul). Further support for the model is provided in research examining age trends in music preferences (Bonneville-Roussy, Rentfrow, Xu \& Potter, 2013), which provides evidence that the five factors generalise across age. This research also found patterns of association between all five MUSIC 
dimensions and personality factors of Openness, Extraversion, Agreeableness and Conscientiousness, aligning with findings of previous research seeking to draw links between music genre preference and personality. Most research in this area has focussed on the Big Five personality traits, summarised in the following sections.

Openness to experience has been shown to be associated with experiencing more intense emotion whilst listening to music (Liljestom, Juslin \& Västfjäll, 2012; Vuoskoski \& Eerola, 2011); preference for a wide range of genres (Rawlings \& Ciancarelli, 1997), rock and heavy metal (Rentfrow \& Gosling, 2003; Swami et al., 2013), and jazz music (Dunn, de Ruyter \& Bouwhuis, 2011). It is positively associated with Mellow, Sophisticated and Intense music (Bonneville-Roussy et al., 2013), Reflective and Complex, Intense and Rebellious dimensions, and has a negative association with preference for Upbeat and Conventional and Energetic and Rhythmic dimensions (Langmeyer, Guglhor-Rudan \& Tarnai, 2012; Rentfrow \& Gosling, 2003). Openness to experience has also been found to have the most robust association with preference for music genres (Zweigenhaft, 2008) along with Extraversion (Miranda, Morizot \& Gaudreau, 2012).

Extraversion has been linked to preference for pop music (Rawlings \& Ciancarelli, 1997), rock music (Dauossis \& McKelvie, 1986), rap and dance music (Dunn et al., 2011). It is associated with Upbeat and Conventional, Energetic and Rhythmic music (Langmeyer et al., 2012; Rentfrow \& Gosling, 2003), and the Unpretentious and Contemporary dimensions of the MUSIC model (Bonneville-Roussy et al., 2013).

Neuroticism is associated with use of music for emotion regulation (Chamorro-Premuzic \& Furnham, 2007); preference for pop music (Dollinger, 1993), classical music (Dunn et al., 2011) and Upbeat and Conventional music (Langmeyer et al., 2012). 
Agreeableness has been shown to be associated with preference for classical music (Dollinger, 1993), soundtrack music (Dunn et al., 2011), Upbeat and Conventional, Energetic and Rhythmic music (Langmeyer et al., 2012, Rentfrow \& Gosling, 2003), and the Unpretentious MUSIC dimension (Bonneville-Roussy et al., 2013).

Conscientiousness has been shown to be negatively correlated with preference for Intense music and positively associated with Unpretentious, Upbeat and Conventional music (Langmeyer et al., 2012; Rentfrow \& Gosling, 2003, Bonneville-Roussy et al., 2013).

Other research has examined associations between rock music and sensation seeking (Litle \& Zuckerman, 1986); self perceived intelligence and preference for classical and jazz music (Chamorro-Premuzic, Swami \& Cermakova, 2010); negative attitude to authority, lower self esteem, and need for uniqueness with a preference for heavy metal (Swami et al., 2013).

Outside of genre categories, some research has explored associations between acoustical attributes of music and personality traits. This includes associations between psychoticism and bass in preferred music (McCown, Keiser, Mulhearn \& Williamson, 1997); Extraversion and preference for strong rhythms, fast tempo, discordant harmony, and positive valence (Cattell \& Saunders, 1954): Openness and preference for slow music; and positive association between Agreeableness, Extraversion and Conscientiousness with major music and fast tempo (Dobrota \& Reic Ercegovac, 2013).

The wealth of research in this area presents compelling evidence that music preference is an expression of personality. Currently the most successful model of music preference is the five dimension MUSIC model. Given its proven robustness, and its incorporation of both music and psychological attributes in addition to genre categories, this model perhaps has the greatest potential to provide insight into the psychology of music preferences (Rentfrow et al., 2011, 2012; Bonneville-Roussy et al., 2013 ). 


\section{Occupation and personality}

The most prominent theory of personality and occupation was first conceptualised by John Holland in 1953, and has since become the most influential theory in the field of vocational psychology (Foutch, McHugh, Bertoch \& Reardon, 2014), with some of the most well-replicated findings in vocational psychology research (Rounds, 1995). The theory (Holland 1997; Holland et al., 1994) describes how interaction with environment, individual and environmental characteristics combine to influence career choices, and that this results in resemblance to a combination of six vocational or interest types consistent across gender and cultural boundaries. These are Realistic, Investigative, Artistic, Social, Enterprising and Conventional - the RIASEC model. Individuals are ascribed to a subtype, each letter representing one type (R, I, A, S, E or C), in order of magnitude from most to least prominent. Thus the first letter of an individual's subtype indicates their dominant personality attributes. Those who share the same subtype are similar in their vocational preferences, and specific occupations may cluster around the dominant type. For example designers and photographers both cluster around the dominant type Artistic (Spokane \& Cruza-Guet, 2005). The following is an overview of the environmental types, attributes and selfdescriptions associated with each primary vocation type (Holland et al., 1994; Spokane \& Cruza-Guet, 2005; Reardon \& Staff, 2010).

Realistic types are practical, physically able but may lack social skills. They are athletic, frank, physically active, stable, humble, practical, uninvestigative, conforming, modest, reserved and self-controlled.

Investigative types are analytical, have good technical and verbal abilities, enjoy problem solving, but may lack leadership ability. They are complex, intellectual, introspective, independent, pessimistic, retiring and reserved. 
Artistic types are unconventional, creative, communicative, liberal, open, original, sensitive and value aesthetics. They are flexible, non-conforming, idealistic, enjoy ambiguity and are averse to systematic and ordered activities.

Social types have interpersonal skills, have concern for the welfare of others, but may be averse to mechanical or technical activity. They are cheerful, communicative, empathetic, kind, patient, outgoing, tactful and warm.

Enterprising types are power oriented, pursue material goals, but may lack scientific or technical ability and avoid routine. They are adventurous, assertive, dominant, persuasive, extraverted, optimistic, energetic and driven.

Conventional types have administrative and organisational ability, dependable, but may lack artistic abilities. They are careful, conforming, conscientious, methodical, defensive, unimaginative and prefer structure.

As with research on music preferences, previous research on occupation and personality has examined relationships between occupation and Big Five personality traits. Costa, McCrae and Holland (1984) found consistent but moderate relationships between RIASEC categories and the Big Five, specifically associations between the Investigative and Artistic type with Openness, and associations between the Social and Enterprising types and Extraversion. De Fruyt and Mervielde (1997) found relationships between the Artistic type and Openness, Enterprising type and Extraversion, and the Social type and Extraversion and Agreeableness. A later meta-analysis highlighted positive relationships of varying strength between the Artistic type and Openness, Enterprising and Social types and Extraversion, the Investigative type and Openness, and the Social type and Agreeableness (Larson, Rottinghaus \& Borgen, 2002). A longitudinal study which measured Big Five traits in children and then examined their occupation 40 years later, found links between those initial measurements and the resulting RIASEC 
category of their occupation as adults (Woods \& Hampson, 2010). Specifically they found Openness and intellect were related to the Investigative and Artistic type, and that Conscientiousness was related to all six types.

\section{Occupation and taste}

There are parallels between the current research and previous work examining personality and taste as a predictor for membership of broadly defined occupational groups. See for example Filer (1986) who found consideration of personality and taste factors improved accuracy in predicting which broad occupational group an individual belongs to (for example clerical, blue-collar, managerial). Note that in Filer's research 'taste' refers to the importance individuals assign to factors such as income, family life and job satisfaction rather than aesthetic preference for e.g. art or music. Peterson and Simkus (1992) found links between music tastes and occupational status groups. For example they found classical music preference was linked to higher status occupations (for example managerial and professional jobs) and preference for country music was liked to lower status occupations (e.g. manual, unskilled). Thus Peterson and Simkus find music tastes act as a 'marker' of occupational status. Higher social status has also been linked to having wider (or more 'omnivorous') tastes than those of lower social status (Peterson \& Kern, 1996), including preference for a wider range of music genres (van Eijck, 2001).

Beyond these examples there is a dearth of research linking occupation with music preferences. The RIASEC model has been used as a theoretical framework for examining personality types of music student teachers (Teachout, 2001). However this work focussed on exploring links between the RIASEC type of the teachers (who were found to be predominantly Artistic, Social and Investigative), and the effectiveness of their teaching, rather than music preferences. No previous research has sought to compare RIASEC occupational personality types and models of music preference. 


\section{Summary and objectives of this research}

In summary, personality is a predictor of both chosen occupation and music preferences. Personality differences have been shown to be related to genre-based dimensions of music preference (most notably the MUSIC model), and also to preference for acoustical attributes of the music. Research focussing on the RIASEC model has provided enduring and well-tested evidence for links between dominant personality traits and RIASEC vocational personality categories. The Desert Island Discs archive is of particular interest due to the public nature of interviewees' expressed music preferences, and that interviewees have a public profile related directly to their chosen occupation. Thus we are situating our investigation in a context where individuals have an interest in managing the impression they convey, and that this relates directly to both their occupation and their music choices.

Our main objective is to examine whether occupation and music preferences are related. We pursue this goal in the context of publicly expressed music preferences of those with a public profile related to their occupation. Specifically we hypothesise that there are 1. significant associations between RIASEC categories of vocational personality and music preference dimensions of the MUSIC model, and 2. significant effects for RIASEC category on acoustical attributes of preferred music.

\section{Methods}

\section{Participants}

Our research examines the music choices and occupation categories of interviewees on Desert Island

Discs from the programme's beginning in April 1942 to the point at which the dataset was collected (February 2014), thus covering a period of just under 72 years. No direct contact was made with 
interviewees, rather their occupations and music choices were established through examination of the programme archive (Desert Island Discs, 2015). In the first analysis presented in this paper, the music choices of 2584 interviewees are examined, whilst in the second analysis the music choices of 2611 interviewees are considered. A detailed rationale for the varying interviewee numbers in each analysis is provided in the 'analysis procedure' section of this paper.

\section{Materials}

Data was extracted from the Desert Island Discs 'castaway archive' (Desert Island Discs, 2015) via Scraperwiki, accessing data produced by Tom Morris in March 2014 (Scraperwiki, 2015). Scraperwiki is a platform for the collection and analysis of publicly available databases. See Marres and Weltervrede (2013) for a discussion on the utility of such platforms in social research. The dataset in its original form is basic, consisting only of the date of broadcast, the name of the interviewee, their occupation, titles of their eight pieces of chosen music, the artist, or if a classical piece, composer and performer. Thus the dataset required significant extension and coding to meet the aims of the current research. This involved coding interviewees by occupation type, gathering acoustical attribute data for each track, and coding music choices by MUSIC dimension. This process is described in the following sections.

Occupation coding. This process was carried out with reference to Holland Occupation Codes (Gottfredson \& Holland, 1996), a supplement to the Holland classification system which cross-references RIASEC codes to seven of the most widely used occupational classifications and information sources in the United States, and which encompasses in the region of 13000 occupational titles. This data is accessible via the Chronicle Career Library (CCL, 2015). Each interviewee's occupation was manually coded according to one of the six RIASEC model primary types, e.g. A for artistic. This approach strikes a balance between allowing a sufficient number of interviewees to be similarly coded, and differentiation between occupations (for example a writer of fiction is assigned primary code A for artistic, whereas a 
technical writer is assigned the primary code I for Investigative). Individuals who appeared in the programme more than once are counted only once, and have a single RIASEC code (there were no instances in the dataset where repeat interviewees had changed occupation between appearances on the show). A list of occupations coded in this process is included in the supplementary information accompanying this manuscript.

Acoustical attributes. Algorithms were written using the Mathworks' Matlab to gather genre and music attribute data for each track from the Echonest Application Programming Interface (http://the.echonest.com/). The query data for each track is returned in JavaScript Object Notation (JSON) format, which is then parsed by the algorithm, making use of JSONlab, an open source JSON toolset for Matlab (JSONlab, 2015). The algorithm makes three discreet queries, the first extracting the artist and track identification codes, the second identifying the artist genre, and a third which gathers the audio summary for each track. This last query makes use of the Echonest music analysis functionality (Jehan \& DesRoches, 2011), gathering data for the following attributes of each track: energy (a perceptual measure of music intensity); tempo; duration; loudness (overall loudness across the whole track in $\mathrm{dB}$ ); valence (musical positiveness as expressed by its acoustical properties); acousticness (presence of acoustic instruments and voice); instrumentalness (the likelihood of containing fewer, or no, sung lyrics); and danceability (a combination of tempo, beat strength, and regularity).

MUSIC coding. Tracks in the dataset were coded according to the genre identified in the above process, and assigned one of the five MUSIC dimension codes (for example a track with a 'rock' genre tag is assigned the MUSIC code I for Intense). Each genre tag gathered from the Echonest was manually checked for accuracy, with reference to the music genre list (Music Genre List, 2015). This timeconsuming process is necessary to ensure the accuracy of the tagging process and to avoid misclassification of entries in the dataset (for example, an entry with the genre tag 'classical' may refer to 
classical music, or a classical poetry recital). Some tracks and genres in the dataset do not feature in the MUSIC scheme (oldies, soundtracks, military, comedy, speech only, and experimental) and as such were not assigned a MUSIC code.

\section{Analysis procedure}

Two analyses were carried out, separately addressing the two aforementioned research hypotheses:

The first analysis aims to establish whether there are significant associations between RIASEC occupation categories and MUSIC genre preference categories. The above data coding process results in a dataset of $\mathrm{N}=10696$ tracks coded by MUSIC category, representing the music choices of 2584 unique interviewees coded for RIASEC occupation type. A Chi Square test for independence was carried out in order to explore associations between occupation and music preference categories. In order to highlight significant associations between RIASEC types and MUSIC dimensions, adjusted residuals (z-scores) are calculated for each cell, and individual significance (p) values for each cell calculated using the approach described in Beasley and Schumacker (1995) and Garcia-Perez and Nunez-Anton (2003). To take account of the multiple comparisons in this analysis (six RIASEC categories compared to five MUSIC categories), a Bonferroni corrected p value of 0.0016 is utilised. Although each interviewee originally identified eight favourite tracks during the programme, the availability of Echonest data results in a dataset with varying numbers of tracks per interviewee (with data for an average of just over 4 tracks per interviewee). Levene's test for homogeneity of variance indicates that there is no significant difference in the variance of track counts between RIASEC categories $(p=0.354)$, supporting our assumption that this factor does not introduce significant bias in the analysis.

The second analysis examines associations between RIASEC occupation categories and acoustical attributes of music choices using a series of ANOVAs. In this analysis, the RIASEC category 
Conventional was excluded due to the very low numbers of interviewees and associated tracks in this category. In addition, non-MUSIC categorised tracks (such as soundtracks, military and oldies) are included in this analysis. This results in a dataset of $\mathrm{N}=12161$ tracks, representing the music choices of 2611 unique interviewees.

\section{Results}

\section{Analysis 1 - RIASEC occupation category vs MUSIC dimension}

Chi Square results indicate significant associations between RIASEC occupation type and MUSIC dimension $\chi^{2}(20)=184.986, p<.001$. Results are shown in Table 1 , which also highlights the varying numbers in each of the RIASEC categories. Notably the majority belong to the Artistic type (reflecting the emphasis on interviewees from the entertainment industry), followed by Social, Enterprising and Investigative. Very few are from the Conventional type. This distribution also speaks to the likelihood of having a public profile when engaged in a certain occupation type. In addition the table highlights the prevalence of Sophisticated music choices in the dataset, which in turn reflects the popularity of classical music (which belongs to this MUSIC category) as chosen by interviewees over the time span of the programme. 
Table 1. Associations between RIASEC vocation types and MUSIC preference dimensions.

\begin{tabular}{|c|c|c|c|c|c|c|c|}
\hline \multirow[t]{2}{*}{ RIASEC category } & & \multicolumn{5}{|c|}{ MUSIC category } & \multirow[t]{2}{*}{ Total } \\
\hline & & Mellow & Unpretentious & Sophisticated & Intense & Contemporary & \\
\hline \multirow[t]{3}{*}{ Artistic } & Count & 328 & 873 & 5291 & 773 & 189 & 7454 \\
\hline & $\%$ within RIASEC & 4.40 & 11.71 & 70.98 & 10.37 & 2.54 & $100 \%$ \\
\hline & Adjusted Residual & -2.44 & $-4.30 *$ & $9.51 *$ & $-6.25^{*}$ & -2.89 & \\
\hline \multirow[t]{3}{*}{ Conventional } & Count & 1 & 0 & 5 & 0 & 0 & 6 \\
\hline & $\%$ within RIASEC & 16.67 & 0.00 & 83.33 & 0.00 & 0.00 & $100 \%$ \\
\hline & Adjusted Residual & 1.38 & -0.93 & 0.80 & -0.89 & -0.42 & \\
\hline \multirow[t]{3}{*}{ Enterprising } & Count & 77 & 156 & 752 & 180 & 46 & 1211 \\
\hline & $\%$ within RIASEC & 6.36 & 12.88 & 62.10 & 14.86 & 3.80 & $100 \%$ \\
\hline & Adjusted Residual & 2.83 & 0.29 & $-4.81 *$ & $3.70^{*}$ & 2.13 & \\
\hline \multirow[t]{3}{*}{ Investigative } & Count & 44 & 65 & 436 & 98 & 11 & 654 \\
\hline & $\%$ within RIASEC & 6.73 & 9.94 & 66.67 & 14.98 & 1.68 & $100 \%$ \\
\hline & Adjusted Residual & 2.48 & -2.13 & -0.84 & 2.74 & -1.84 & \\
\hline \multirow[t]{3}{*}{ Realistic } & Count & 2 & 19 & 14 & 13 & 1 & 49 \\
\hline & $\%$ within RIASEC & 4.08 & 38.78 & 28.57 & 26.53 & 2.04 & $100 \%$ \\
\hline & Adjusted Residual & -0.21 & $5.53^{*}$ & $-5.96 *$ & $3.25^{*}$ & -0.34 & \\
\hline \multirow[t]{3}{*}{ Social } & Count & 54 & 237 & 792 & 182 & 57 & 1322 \\
\hline & $\%$ within RIASEC & 4.08 & 17.93 & 59.91 & 13.77 & 4.31 & $100 \%$ \\
\hline & Adjusted Residual & -1.18 & $6.21^{*}$ & $-6.88 *$ & 2.56 & $3.43^{*}$ & \\
\hline \multirow[t]{2}{*}{ Total } & Count & 506 & 1350 & 7290 & 1246 & 304 & 10696 \\
\hline & $\%$ within RIASEC & 4.73 & 12.62 & 68.16 & 11.65 & 2.84 & $100 \%$ \\
\hline
\end{tabular}


The varying numbers in the RIASEC categories make it difficult to unpick associations between RIASEC and MUSIC categories in Table 1. In order to explore these associations further, post hoc analysis was carried out to produce adjusted residuals (z-scores) for each cell. Absolute values in excess of 1.96 indicate a relationship significant to a confidence level of $<.05$, indicating where observed cell values differ significantly from expected values, and therefore significant associations between the associated RIASEC and MUSIC variables. Individual significance (p) values for each cell were also calculated from the adjusted residual values (Beasley \& Schumacker, 1995; Garcia-Perez \& Nunez-Anton, 2003). Where stated, the following results are significant to a Bonferroni adjusted significance of 0.0016 . Where individual $\mathrm{p}$ values have not reached significance at the corrected level, associations are significant to the .05 level, indicated by an adjusted residual value in excess of $+/-1.96$.

The Artistic type is significantly positively associated with Sophisticated music. This type is also significantly negatively associated with Intense and Unpretentious music. It is also negatively associated with Mellow and Contemporary music, although this did not reach the corrected significance level.

The Enterprising type is significantly negatively associated with Sophisticated music, and significantly positively associated with Intense music. It is also positively associated with Mellow and Contemporary music, although not at the corrected significance level.

The Investigative type is positively associated with Mellow and Intense music, and negatively associated with Unpretentious music. However no associations for this RIASEC type reached the significance at the corrected level.

The Realistic type is significantly positively associated with Unpretentious and Intense music, and significantly negatively associated with Sophisticated music. 
The Social type is significantly negatively associated with Sophisticated music, and significantly positively associated with Unpretentious and Contemporary music. It is also positively associated with Intense music, but this association does not reach significance at the corrected level.

\section{Analysis 2 - RIASEC occupation category vs music attributes}

There is a main effect for RIASEC category on the acoustical attributes of energy, loudness, song duration, valence, acousticness, instrumentalness and danceability and tempo. Mean and standard deviation values for these attributes, for each RIASEC category, are shown in Table 2. 
Table 2. Mean and Standard deviation values for acoustical attributes by RIASEC category

\begin{tabular}{|c|c|c|c|c|c|}
\hline & Artistic & Enterprising & Investigative & Realistic & Social \\
\hline & $\mathrm{M}(S D)$ & $\mathrm{M}(S D)$ & $\mathrm{M}(S D)$ & $\mathrm{M}(S D)$ & $\mathrm{M}(S D)$ \\
\hline energy & $0.26(0.22)$ & $0.31(0.24)$ & $0.28(0.23)$ & $0.42(0.24)$ & $0.3(0.23)$ \\
\hline tempo (bpm) & $105.06(29.68)$ & $106.95(30.86)$ & $107.17(29.74)$ & $113.76(21.46)$ & $106.33(29.84)$ \\
\hline acousticness & $0.82(0.26)$ & $0.75(0.3)$ & $0.77(0.3)$ & $0.57(0.4)$ & $0.76(0.3)$ \\
\hline instrumentalness & $0.37(0.39)$ & $0.33(0.39)$ & $0.39(0.39)$ & $0.16(0.31)$ & $0.32(0.38)$ \\
\hline duration (s) & $486.43(663.37)$ & $471.44(682.12)$ & $503.3(723.21)$ & $288.91(381.03)$ & $404.11(554.81)$ \\
\hline loudness (dB) & $-16.78(6.41)$ & $-15.62(6.24)$ & $-16.5(6.18)$ & $-12.6(5.23)$ & $-16(6.46)$ \\
\hline valence & $0.34(0.27)$ & $0.36(0.27)$ & $0.36(0.27)$ & $0.49(0.25)$ & $0.37(0.27)$ \\
\hline danceability & $0.38(0.18)$ & $0.39(0.18)$ & $0.39(0.18)$ & $0.45(0.15)$ & $0.4(0.18)$ \\
\hline
\end{tabular}


Figures 1-4 further highlight patterns in the attributes by RIASEC category: Figure 1 shows mean values for energy, acousticness, instrumentalness, valence and danceability; mean tempo is shown in Figure 2; mean duration (in seconds) in Figure 3; and mean loudness (in dB) in Figure 4.

Energy. There is a significant effect for RIASEC type on energy in music choices, $F(4)=23.77, p<.001$. Those in the Realistic type choose music which is of significantly higher energy than other types $(p=$ 0.023). Artistic types choose music with lowest energy, and of significantly lower energy than Enterprising, Realistic and Social types $(p<.001)$.

Tempo. There is a significant effect for Holland type on tempo in music choices, $F(4)=3.947, p=.004$. Those in the Realistic type choose music which is of higher tempo than other groups, and this approaches significance in relation to the Artistic type $(p=0.05)$. Those in the Artistic type choose music with the lowest tempo

Loudness. There is a significant effect for RIASEC type on loudness in music choices, $F(4)=17.699, p<$ .001. Those in the Realistic type choose significantly louder music than all other groups $(p=.007)$. Artistic types chose music with significantly lower loudness levels than Enterprising, Realistic and Social types $(p<.001)$. Investigative types also choose music with lower loudness levels, significantly lower than Enterprising $(p=.023)$ and Realistic types $(p<.001)$.

Song duration. There is a significant effect for RIASEC type on song duration, $F(4)=9.851, p<.001$. Those in the Realistic type choose significantly shorter songs than Artistic $(p=.005)$, Enterprising $(p=$ $.018)$ and Investigative types $(p=.005)$, these types having chosen the longest tracks.

Valence. There is a significant effect for RIASEC type on valence of music choices, $F(4)=7.444, p<$ .001. Music chosen by the Realistic type is significantly more positive than all other types (Artistic $p=$ 
0.01 , Enterprising $p=0.09$, Investigative $p=0.08$, Social, $p=.016$ ). The saddest music is chosen by the Artistic type, and this is significantly sadder than Realistic and Social types $(p=.005)$.

Acousticness. There is a significant effect for RIASEC type on acousticness in music choices, $F(4)=$ $29.229, p<.001$. Higher values for acousticness point to the presence of acoustic instruments and voice, as opposed to electronic instruments. Artistic types choose significantly more acoustic music than all other RIASEC types $(p=.001)$. Those in the Realistic type choose music which is of significantly lower mean acousticness than all other types (Artistic, $p=.001$; Enterprising, Investigative, Social, $p=.020$ ), pointing to a greater preference for electronic music.

Instrumentalness, There is a significant effect for RIASEC type on instrumentalness in music choices $F(4)=14.951, p<.001$. Higher values for instrumentalness indicate the music contains fewer, or no, sung lyrics. Realistic types choose significantly less instrumental music than all other types $(p=.006)$. Artistic and Investigative types choose the most instrumental music, with Investigative types choosing music that is significantly more instrumental than Enterprising $(p=.030)$, Realistic and Social types $(p=.001)$.

Danceability. There is a significant effect for RIASEC type on the danceability of music choices, $F(4)=$ $4.578, p=.001$. Danceability is an indication of tempo, rhythm stability and beat strength. Those in the Realistic type choose the most danceable music, approaching significance when compared to the Realistic type $(p=.053)$. Artistic and Investigative types choose the least danceable music. 


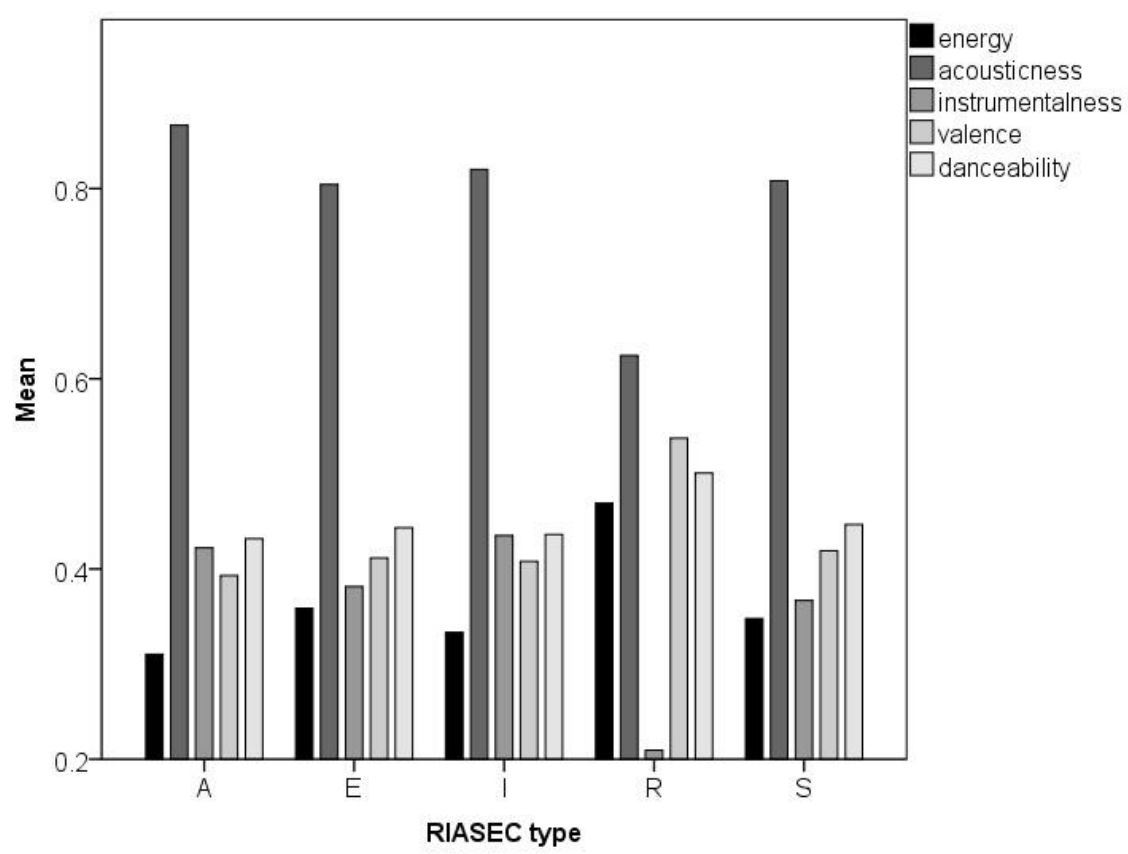

Figure 1. Mean values for music attributes by vocation type, indicating for example the differences between energy, acousticness and instrumentalness between Realistic and Artistic types. 


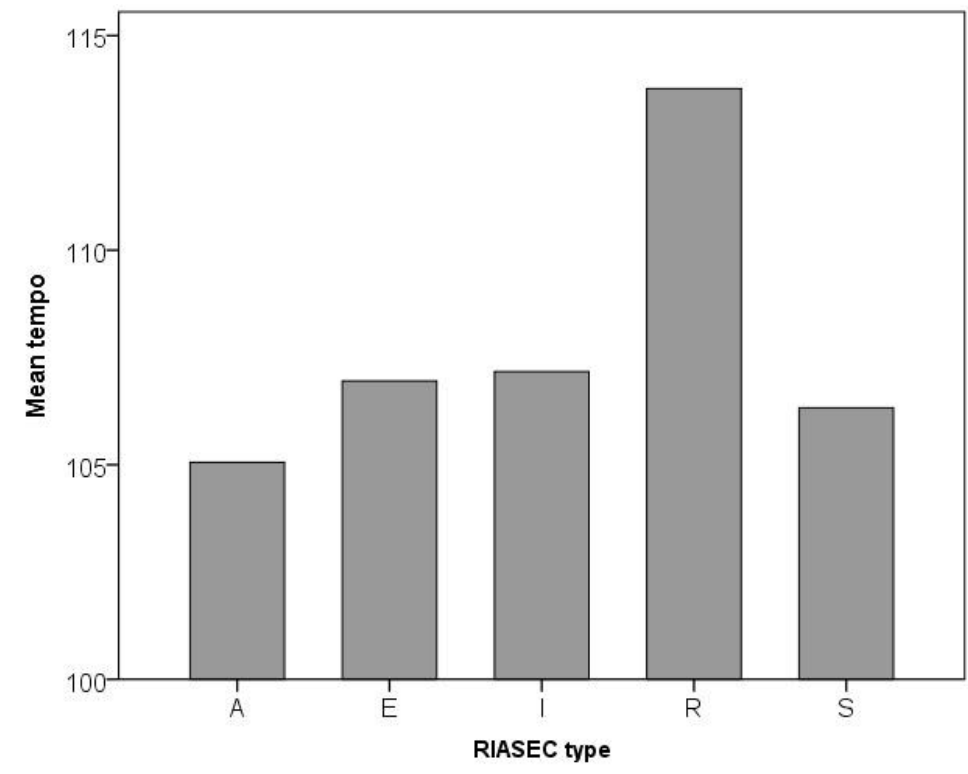

Figure 2. Mean tempo (in bpm) by RIASEC type, demonstrates the significantly preference for higher tempo music by those in the Realistic type. 


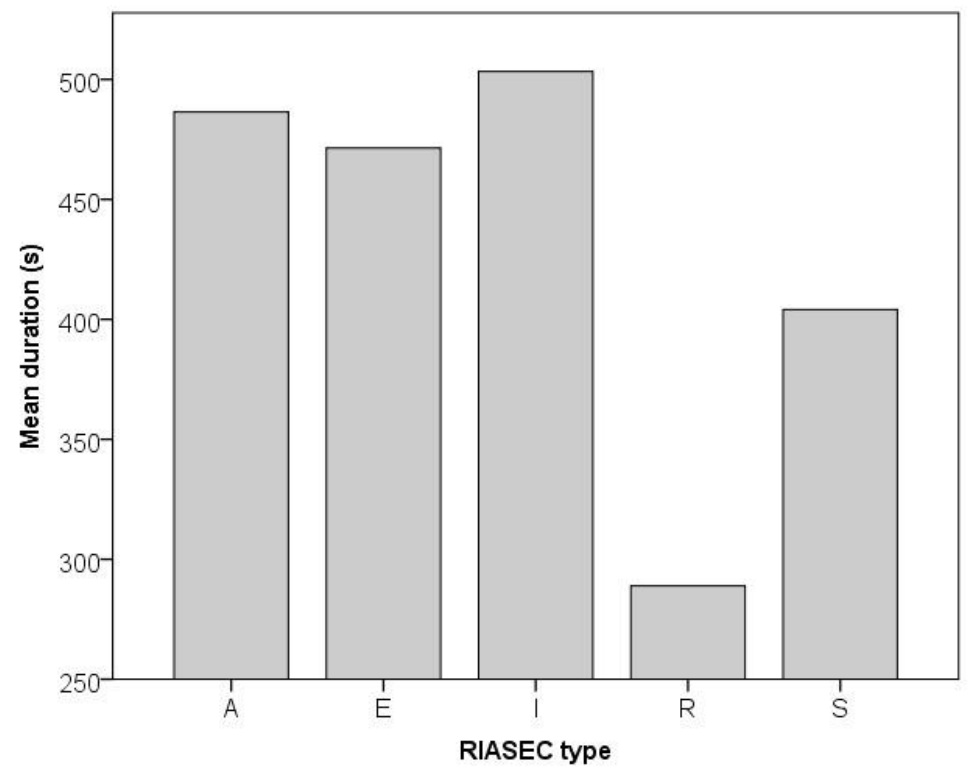

Figure 3. Mean song duration (in seconds) by RIASEC type. Those in the Investigative type have a preference for longer song durations, whereas Realistic types prefer shorter songs. 


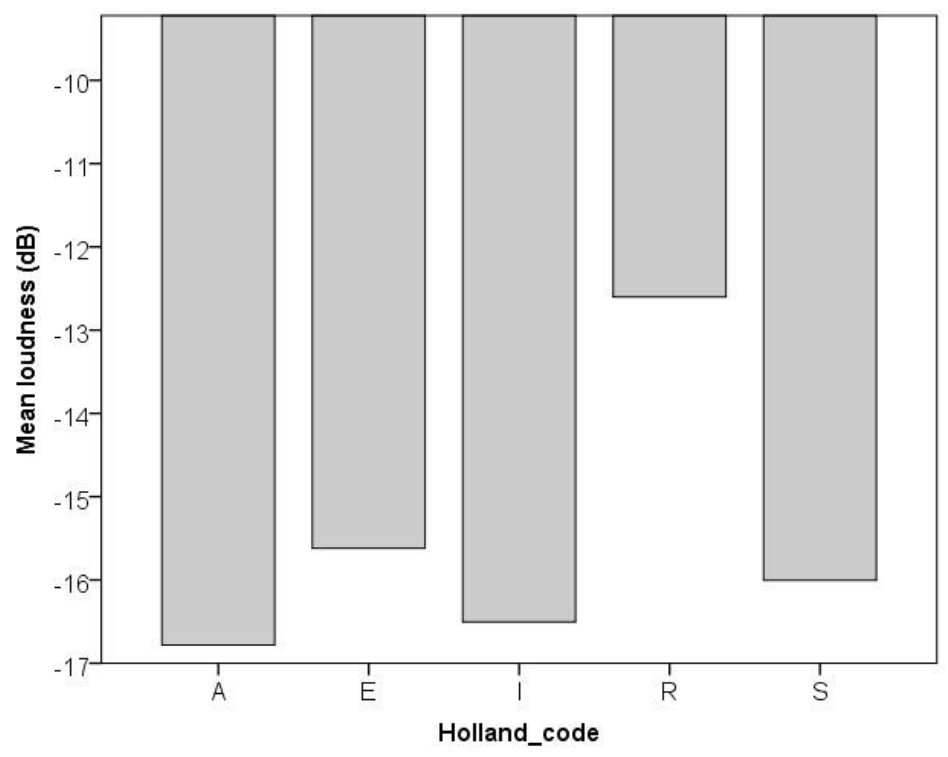

Figure 4. Mean loudness (in dB) by RIASEC type. Louder tracks are preferred by the Realistic type, quieter tracks by the Artistic type. 


\section{Discussion}

\section{Relationships between RIASEC and MUSIC dimensions}

The results highlight significant associations between the RIASEC and MUSIC models of occupation and music preference, thus supporting our hypothesis that, within this dataset, occupation and music preferences are related. The current research did not directly measure personality traits of interviewees on the Desert Island Discs programme therefore a rigorous comparison of shared personality traits is not possible. However both the RIASEC and MUSIC models are seated in research on individual differences, and are effectively used in this research as a proxy for personality. Although we cannot speculate on the causality of associations on the strength of these results alone, they invite discussion on the possibility that observed associations may be mediated by personality. The following discussion explores the personality traits which have been associated with RIASEC types and music preference dimensions in previous research, and how these align with results from the current research.

The Artistic occupation type is positively associated with the Sophisticated MUSIC dimension, both of which have been shown to be positively related to Openness in previous research (De Fruyt \& Mervielde, 1997; Larson et al., 2002; Bonneville-Roussy et al., 2013; Langmeyer et al., 2012). The results also show this occupation type is negatively associated with the Unpretentious music dimension, aligning with previous research suggesting those who are open to experience dislike Upbeat and Conventional music (Langmeyer et al., 2012). However in our results the Artistic type is negatively associated with Intense music, disagreeing with previous research which has found Intense music to be positively associated with Openness (Rentfrow \& Gosling, 2003; Swami et al., 2013; Bonneville-Roussy et al., 2013).

The Realistic type was found to be significantly positively associated with the Unpretentious MUSIC dimension. These categories have both been positively associated with Conscientiousness in previous 
research (Woods \& Hampson, 2010; Langmeyer et al., 2012; Rentfrow \& Gosling, 2003; BonnevilleRoussy et al., 2013). However again there is disagreement with previous research in that we find the Realistic type also to be positively associated with Intense music, which has previously been shown to be negatively correlated with Conscientiousness (Langmeyer et al., 2012; Rentfrow \& Gosling, 2003; Bonneville-Roussy et al., 2013).

The Social type is significantly positively associated with the Unpretentious and Contemporary music dimensions, with which Extraversion and Agreeableness have both been positively associated in previous research (De Fruyt \& Mervielde, 1997; Larson et al., 2002; Rawlings \& Ciancarelli, 1997; Dunn et al., 2011; Langmeyer et al., 2012; Rentfrow \& Gosling, 2003; Bonneville-Roussy et al., 2013). However the significantly negative association between the Social type and Sophisticated music is in contrast to previous research which found a positive relationship between Agreeableness and preference for classical music (Dollinger, 1993);

The Enterprising type has been associated with Extraversion in previous research (De Fruyt \& Mervielde, 1997; Larson et al., 2002; Costa et al., 1984). Our results indicate a significant association between this type and Intense music, which has previously been shown to be positively associated with Extraversion (Dauossis \& McKelvie, 1986).

In summary, the results provide evidence for several significant positive and negative associations between RIASEC types and MUSIC dimensions. No previous research has sought to align these models, thus there is no body of existing results to compare our results to directly. However the preceding discussion has examined these relationships in the context of previous research which has found relationships between personality traits and, separately, occupation types and music preference dimensions. Some of the results are consistent with previous findings in this regard (for example links between the Artistic type and Sophisticated music, both previously associated positively with Openness). 
Some, such as the positive association between the Realistic type and Intense music, disagree with previous research which has found they have opposing relationships with Conscientiousness. Future research should focus on examining whether there are indeed robust personality factors which mediate relationships between occupation type and music preference dimensions, and we propose the RIASEC and MUSIC models may be the most appropriate and relevant framework within which to study this issue.

\section{Relationships between RIASEC and acoustical attributes}

The results indicate a main effect for RIASEC occupation type and acoustical attributes of chosen music. A clear picture emerges from these results in terms of the opposite characteristics of Artistic and Realistic occupation types. The Artistic type is positively associated with Sophisticated music, and negatively associated with Intense and Unpretentious music. This type chose music which has lowest mean energy and loudness levels, highest mean acousticness, and high mean instrumentalness. These attributes most reflect those found in previous research to characterise the Sophisticated music dimension (Rentfrow et al., 2012; Bonneville-Roussy et al., 2013). These results suggest a clear link between Artistic type and the Sophisticated MUSIC dimension, which is reflected in preference for acoustical attributes of the music. However the Artistic type choose the most negatively valenced music, in contrast to previous research which found the Sophisticated dimension to be characterised by positive attributes (Rentfrow et al., 2012). The Realistic type was found to have a negative association with Sophisticated music and a positive one with Unpretentious and Intense music. This type choose music with the highest mean energy and loudness, fastest mean tempo, which is predominantly electric, least instrumental, and most danceable. This type is found to be positively associated with two MUSIC dimensions, and these attributes clearly reflect the loud, fast, percussive and vocal characteristics of the Intense dimension rather than the soft, acoustic, low energy characteristics of the Unpretentious dimension (Rentfrow et al., 2012; 
Bonneville-Roussy et al., 2013). The results do however suggest those in the Realistic type have a preference for more positive music, something which is more associated with the Unpretentious rather than the Intense dimension. Together, these results highlight that the Artistic and Realistic types are characterised by their music preferences in terms of acoustical attributes of the music, and that these are particularly reflected in attributes known to characterise the MUSIC dimensions Sophisticated and Intense.

As in the preceding section, any comparison of associated personality traits must be handled with care given that this research did not take direct personality measurements. However it is tempting to suggest the possibility of potential relationships between occupation type, personality, and music attribute preferences based on results provided by previous research. The Artistic type, previously found to be positively associated with Openness (De Fruyt \& Mervielde, 1997; Larson et al., 2002; Woods \& Hampson, 2010), choose music with the slowest mean tempo. This supports research which has found links between Openness and preference for slow music (Dobrota \& Reic Ercegovac, 2013). The Investigative type, also found to be associated with Openness (Larson et al., 2002; Costa et al., 1984) choose music which is similarly low in energy and loudness. The Realistic type has been associated with Conscientiousness (Woods \& Hampson, 2012), previously found to be associated with preference for major music and fast tempo (Dobrota \& Reic Ercegovac, 2013), a relationship supported in our results.

In summary, these results demonstrate the effectiveness of considering acoustical music attributes when elucidating music preferences in the context of individual differences. This is reflected in the relatively recent incorporation of auditory attributes in the MUSIC model (Rentfrow et al., 2011; Rentfrow et al., 2012; Bonneville-Roussy et al., 2013), currently the most popular and robust model of music preferences and individual differences. The results demonstrating a main effect for RIASEC dimension on acoustical 
attributes also suggest this approach may have particular utility in the future study of relationships between occupation and music preferences.

\section{Limitations and Future Research}

This research has several limitations. The main objective is to examine relationships between occupation and music preferences in the context of publicly expressed music choices. The coded dataset is sufficient to support this investigation, and the results provide sufficient evidence to support the hypothesis that occupation is related to music preferences in terms of MUSIC dimensions and acoustical attributes. However no explicit measurements of personality were made in the original interviews or during the current research. This necessitates informal discussion of possible mediating effects of personality rather than a detailed exploration. These tentative initial results do however suggest the basis for future work which might empirically examine personality traits as a mediating factor in the relationship between occupation and music preferences. Future research might also consider more nuanced aspects of the RIASEC model. For example examining participants with high and low consistency (dictated by the proximity of first two letters of the RIASEC sub-code).

This research involved the analysis of an existing dataset (the Desert Island Discs archive), and as such we have no control over the number of participants in each RIASEC category. In practice, the numbers in RIASEC and MUSIC categories vary considerably. For example the large proportion of interviewees in the Artistic type, and predominance of classical (Sophisticated) music, both of which reflect the nature of interviewees most featured in the programme and music choices across the 72 year period which was studied. In addition, although the Echonest database is perhaps the largest and most comprehensive music platform currently available, it does not contain data on every single track ever chosen in the Desert Island Discs programme. However the completed dataset is still considerable, encompassing data for 
between 10000 and 12000 tracks in the two analyses, representing the music choices of around $88 \%$ of interviewees who had appeared on the programme at the time of gathering the data.

The Desert Island Discs database is the focus for future research by the authors. It is a valuable record of changing musical preference over generations, something which has been the focus of recent research on preferred music (Krumhansl \& Zupnick, 2013). Given the autobiographical nature of the programme, it is suited to more in-depth exploration of participants' relationship with music which has played an important role in their lives. Our relationship with our favourite music is complex and involves several contributing musical and extra-musical factors, including familiarity, personal meaning and associated memories (Lamont, 2011; Miell, MacDonald \& Hargreaves, 2005). Recordings of a large proportion of episodes are available, and one might argue each episode represents a semi-structured interview exploring the life experiences of the interviewee, the role music has played in their lives and the reasons why. Thus one approach to future exploration of the archive is transcription of interviews and subsequent discourse analysis.

\section{Funding}

This research received no specific grant from any funding agency in the public, commercial or not-forprofit sectors. 


\section{References}

British Broadcasting Corporation (2015). Desert Island Discs. Retrieved from http://www.bbc.co.uk/programmes/b006qnmr

Beasley, T. M., \& Schumacker, R. E. (1995). Multiple regression approach to analyzing contingency tables: Post hoc and planned comparison procedures. The Journal of Experimental Education, 64(1), 7993.

Bonneville-Roussy, A., Rentfrow, P.J., Xu, M.K. \& Potter, J. 2013. Music Through the Ages: Trends in Musical Engagement and Preferences From Adolescence Through Middle Adulthood. Journal of Personality and Social Psychology, Vol. 105, No. 4, 703-717.

Cattell, R. B., \& Saunders, D. R. (1954). Musical preferences and personality diagnosis: I. A factorization of one hundred and twenty themes. The Journal of Social Psychology, 39(1), 3-24.

CCL (2015). Chronicle Career Library, Retrieved from

http://www.chroniclecareerlibrary.com/CGP/CGP/Lists/all.html

Chamorro-Premuzic, T., \& Furnham, A. (2007). Personality and music: Can traits explain how people use music in everyday life? British Journal of Psychology, 98(2), 175-185.

Chamorro-Premuzic, T., Swami, V., \& Cermakova, B. (2010). Individual differences in music consumption are predicted by uses of music and age rather than emotional intelligence, neuroticism, extraversion or openness. Psychology of Music, 40(3), 285-300

Cohen, L., \& Duberley, J. (2013). Constructing careers through narrative and music: An analysis of Desert Island Discs. Journal of Vocational Behavior 82(3), 165-175. 
Costa, P. T., McCrae, R. R., \& Holland, J. L. (1984). Personality and vocational interests in an adult sample. Journal of Applied Psychology, 69, 390-400

Daoussis, L., \& McKelvie, S. J. (1986). Musical Preferences and Effects of Music on a Reading Comprehension Test for Extraverts and Introverts. Perceptual and motor skills, 62(1), 283-289.

De Fruyt, F., \& Mervielde, I. (1997). The five-factor model of personality and Holland's RIASEC interest types. Personality and individual differences, 23(1), 87-103.

Desert Island Discs (2015). http://www.bbc.co.uk/radio4/features/desert-island-discs/find-a-castaway Dobrota, S., \& Reic Ercegovac, I. (2014). Students' Musical Preferences: The Role of Music Education, Characteristics of Music and Personality Traits. Hrvatski časopis za odgoj i obrazovanje, 16(2), 363-384.

Dollinger, S. J. (1993). Research note: Personality and music preference: extraversion and excitement seeking or openness to experience?. Psychology of music, 21(1), 73-77.

Dunn, P. G., de Ruyter, B., \& Bouwhuis, D. G. (2011). Toward a better understanding of the relation between music preference, listening behavior, and personality. Psychology of Music, 40(4), 411-428.

Filer, R. K. (1986). The role of personality and tastes in determining occupational structure. Industrial \& Labor Relations Review, 39(3), 412-424.

Foutch, H., McHugh, E. R., Bertoch, S. C., \& Reardon, R. C. (2014). Creating and using a database on Holland's theory and practical tools. Journal of Career Assessment, 22(1), 188-202.

GarcIa-Perez, M. A., \& Nunez-Anton, V. (2003). Cellwise residual analysis in two-way contingency tables. Educational and psychological measurement, 63(5), 825-839.

Gottfredson, G. D., \& Holland, J. L. (1996). Dictionary of Holland occupational codes. Psychological Assessment Resources Inc. 
Hargreaves, D.J., Miell, D., \& MacDonald, R. (2002). What are musical identities, and why are they important?, in R. MacDonald, D. Hargreaves, \& D. Miell (eds) Musical Identities (pp.1-20). Oxford: Oxford University Press.

Harrington, J., Palethorpe, S., \& Watson, C.I. (2007). Age-related changes in fundamental frequency and formants: a longitudinal study of four speakers. Interspeech 2007, 2753-2756.

Heritage. J. (1998). Oh-prefaced responses to inquiry. Language in Society, 27, 291-334.

Holland, J. L. (1994). Self-directed search. Odessa, FL: Psychological Assessment Resources.

Holland, J. L. (1997). Making vocational choices: A theory of vocational personalities and work environments. Odessa, FL: Psychological Assessment Resources.

Holland, J. L., Powell, A. B., \& Fritzsche, B. A. (1994). The self-directed search (SDS). Psychological Assessment Resources.

Jehan, T., \& DesRoches, D. (2011). The Echo Nest Analyzer Documentation. Retrieved from http://developer.echonest.com/docs/v4/_static/AnalyzeDocumentation.pdf.

JSONlab (2015). JSONLab: a toolbox to encode/decode JSON files in Matlab/Octave. Retrieved from http://uk.mathworks.com/matlabcentral/fileexchange/33381-jsonlab--a-toolbox-to-encode-decode-jsonfiles-in-matlab-octave

Krumhansl, C.L. \& Zupnick, J.A. (2013). Cascading Reminiscence Bumps in Popular Music. Psychological Science, 24(10), 2057-2068.

Lamont, A. (2011). University students' strong experiences of music: Pleasure, engagement, and meaning. Musicae Scientiae, 15: 229-249 
Langmeyer, A., Guglhör-Rudan, A., \& Tarnai, C. (2012). What Do Music Preferences Reveal About Personality? A Cross-Cultural Replication Using Self-Ratings and Ratings of Music Samples. Journal of Individual Differences, 33(2), 119-130.

Larson, L. M., Rottinghaus, P. J., \& Borgen, F. H. (2002). Meta-analyses of Big Six interests and Big Five personality factors. Journal of Vocational Behavior,61(2), 217-239.

Liljeström, S., Juslin, P. N., \& Västfjäll, D. (2013). Experimental evidence of the roles of music choice, social context, and listener personality in emotional reactions to music. Psychology of Music, 41(5), 579599.

Litle, P., \& Zuckerman, M. (1986). Sensation seeking and music preferences. Personality and individual differences, 7(4), 575-578.

MacDonald R.A.R., Hargreaves, D.J. \& Miell, D. (2002). Musical Identities. Oxford: Oxford University Press.

MacDonald R.A.R., Hargreaves, D.J. \& Miell, D. (in press). The Handbook of Musical Identities. Oxford: Oxford University Press.

Marres, N., \& Weltevrede, E. (2013). Scraping the Social? Issues in live social research. Journal of Cultural Economy, 6(3), 313-335.

McCown, W., Keiser, R., Mulhearn, S. \& Williamson, D. (1997). The Role of Personality and Gender in Preference for Exaggerated Bass in Music', Personality and Individual Differences 23: 543-547.

Miell, D., MacDonald R.A.R., \& Hargreaves, D.J.(2005). Musical Communication. Oxford: Oxford University Press.

Miranda, D., Morizot, J., \& Gaudreau, P. (2010). Personality Metatraits and Music Preferences in Adolescence: A Pilot Study. International Journal of Adolescence and Youth, 15(4), 289-301. 
Mullany, L. (1999). Linguistic politeness and sex differences in BBC radio 4 broadcast interviews. Leeds Working Papers in Linguistics and Phonetics 7: 119-145.

Music Genre List (2015). Retrieved from http://www.musicgenreslist.com/

North, A. C., Hargreaves, D. J., \& O’Neill, S. A. (2000). The importance of music to adolescents. British Journal of Educational Psychology, 70, 255-272.

North, A. C., \& Hargreaves, D. J. (2007). Lifestyle correlates of musical preference: 1. Relationships, living arrangements, beliefs, and crime. Psychology of music, 35(1), 58-87.

Orbach, S. (2008). Work is where we live: Emotional literacy and the psychological dimensions of the various relationships there. Emotion, Space and Society 1.1: 14-17.

Peterson, R. A., \& Simkus, A. (1992). How Musical Tastes Mark Occupational Status Groups. In M. Lamont (Ed.), Cultivating differences: Symbolic boundaries and the making of inequality (pp. 152-186). University of Chicago Press.

Peterson, R. A., \& Kern, R. M. (1996). Changing highbrow taste: From snob to omnivore. American sociological review, 900-907.

Rawlings, D., \& Ciancarelli, V. (1997). Music preference and the five-factor model of the NEO Personality Inventory. Psychology of Music, 25(2), 120-132.

Reardon, R. C., \& Staff, P. A. R. (2010). The Self-Directed Search Interpretive report. General information: summary Codes.-2001.

Rentfrow, P.J., \& Gosling, S.D. (2003). The Do Re Mi's of Everyday Life: The Structure and Personality Correlates of Music Preferences. Journal of Personality and Social Psychology, 84(6), 1236-1256

Rentfrow, P. J., \& Gosling, S. D. (2006). Message in a ballad the role of music preferences in interpersonal perception. Psychological science, 17(3), 236-242. 
Rentfrow, P. J., \& Gosling, S. D. (2007). The content and validity of music-genre stereotypes among college students. Psychology of Music, 35(2), 306-326.

Rentfrow, P. J., Goldberg, L. R., \& Levitin, D. J. (2011). The structure of musical preferences: a fivefactor model. Journal of personality and social psychology, 100(6), 1139-1157.

Rentfrow, P. J., Goldberg, L. R., Stillwell, D. J., Kosinski, M., Gosling, S. D., \& Levitin, D. J. (2012). The song remains the same: A replication and extension of the MUSIC model. Music perception, 30(2), 161-185.

Reubold, U., Harrington, J., \& Kleber, F. (2010). Vocal aging effects on F0 and the first formant: a longitudinal analysis in adult speakers. Speech Communication, 52(7), 638-651.

Rounds, J. (1995). Vocational interests: Evaluating structural hypotheses. In D. J. Lubinski \& R. V. Dawis (Eds.), Assessing individual differences in human behavior: New concepts, methods, and findings (pp. 177-232). Palo Alto, CA: Davies-Black Publishing.

Scraperwiki (2015). Retrieved from https://scraperwiki.com/

Spokane, A. R., \& Cruza-Guet, M. C. (2005). Holland's theory of vocational personalities in work environments. Career development and counseling: Putting theory and research to work, 24-41.

STOMPR (2015). Goz Lab, the Gosling Laboratory web page. Retrieved from http://gosling.psy.utexas.edu/

Swami, V., Malpass, F., Havard, D., Benford, K., Costescu, A., Sofitiki, A., \& Taylor, D. (2013). Metalheads: The influence of personality and individual differences on preference for heavy metal. Psychology of Aesthetics, Creativity, and the Arts, 7(4), 377.

Tarrant, M., North, A.C., \& Hargreaves, D.J. (2002). 'Youth Identity and Music', in R. A.R. MacDonald, D.J. Hargreaves and D. Miell (Eds) Musical Identities (pp.134-50). Oxford: Oxford University Press. 
Teachout, D. J. (2001). The relationship between personality and the teaching effectiveness of music student teachers. Psychology of Music, 29(2), 179-192.

Tekman, H. G., \& Hortacsu, N. (2002). Music and social identity: Stylistic identification as a response to musical style. International Journal of Psychology, 37, 277-285.

Van Eijck, K. (2001). Social differentiation in musical taste patterns. Social forces, 79(3), 1163-1185.

Voida, A., Grinter, R., \& Ducheneaut, N. (2006). Social practices around iTunes. In O’Hara and Brown (eds.) Consuming Music Together: Social and Collaborative Aspects of Music Consumption Technologies, (pp. 57-84). Springer, Netherlands.

Vuoskoski, J. K., \& Eerola, T. (2011). Measuring music-induced emotion A comparison of emotion models, personality biases, and intensity of experiences. Musicae Scientiae, 15(2), 159-173.

Warlick, C. (2006). Social implications of iPod use on a large university campus. In Proceedings of the $9^{\text {th }}$ International Conference on Music Perception and Cognition, Baroni et al.. (eds.), pp. 1578. University of Bologna, Italy.

Wheeler, B. L. (1985). Relationship of personal characteristics to mood and enjoyment after hearing live and recorded music and to musical taste. Psychology of Music, 13(2), 81-92.

Woods, S. A., \& Hampson, S. E. (2010). Predicting adult occupational environments from gender and childhood personality traits. Journal of Applied Psychology, 95(6), 1045.

Zweigenhaft, R. L. (2008). A do re mi encore: A closer look at the personality correlates of music preferences. Journal of individual differences, 29(1), 45-55. 
RIASEC occupations within the dataset

$\begin{array}{ll}\text { academic } & \text { filmmaker } \\ \text { actor } & \text { food expert } \\ \text { administrator } & \text { forester } \\ \text { adventurer } & \text { hairdresser } \\ \text { animal trainer } & \text { historian } \\ \text { animator } & \text { horse breeder } \\ \text { architect } & \text { horticulturalist } \\ \text { artist } & \text { impresario } \\ \text { artistic director } & \text { journalist } \\ \text { auctioneer } & \text { legal/lawyer } \\ \text { broadcaster } & \text { lyricist } \\ \text { business person } & \text { musician } \\ \text { campaigner } & \text { performer } \\ \text { chef } & \text { photographer } \\ \text { comedian } & \text { pilot } \\ \text { composer } & \text { poet } \\ \text { counsellor } & \text { police } \\ \text { critic } & \text { politician } \\ \text { dancer } & \text { producer (film) } \\ \text { designer } & \text { public relations } \\ \text { diplomat } & \text { religious } \\ \text { director (of organisation) } & \text { scientist } \\ \text { director (film) } & \text { singer } \\ \text { director (theatre) } & \text { social worker } \\ \text { doctor } & \text { sportsperson } \\ \text { editor } & \text { stylist } \\ \text { educationalist } & \text { vet } \\ \text { engineer } & \text { voice coach } \\ \text { explorer } & \text { writer } \\ \text { farmer } & \text { zoo keeper } \\ \text { fashion industry professing } & \\ \text { a } & \\ \text { a } & \end{array}$

fashion industry professional 